\title{
Challenges in Malaria Diagnosis and Elimination: Case Study in a Rural Community of Gombe State
}

\section{${ }^{1}$ Igwe, Michael A., ${ }^{2}$ Lynn Maori, ${ }^{3}$ Abdullateef Jimoh, ${ }^{4}$ Seth Gushit Longshit and ${ }^{5}$ Atahiru Adamu}

${ }^{1}$ Peace House Medical Mission, Bethany Medical Center Gboko, Benue State, Nigeria

${ }^{2}$ Microbiology Department, Infectious Diseases Hospital Zambuk, Gombe State

${ }^{3}$ World Health Organization, FCT Branch, Nigeria

${ }^{4}$ School of Nursing Jos, Plateau State

${ }^{5}$ School of Nursing and Midwifery, Gombe State

\section{ARTICLE INFO}

Article No.: 122918185

Type: Research

DOI: 10.15580/GJEPH.2019.1.122918185

Submitted: $29 / 12 / 2018$

Accepted: 03/01/2019

Published: 04/02/2019

${ }^{*}$ Corresponding Author

Lynn Maori

E-mail: lynnmaori09@gmail.

Com

Keywords: Malaria Eradication; Control of malaria; Malariaeliminating countries; Controlled low-endemic malaria

\section{ABSTRACT}

Malaria is perhaps even tougher to combat than HIV or tuberculosis because of its multiple distinct life-cycle stages and its genetic complexity, which allows Plasmodium to adapt rapidly to drugs and to or immune system's efforts to render it ineffective. With billions of parasites circulating in a single human host, Plasmodium species are poised to resist immunological and chemotherapeutic attacks. With the aid of mosquito vectors, a single infected can transmit to hundreds of other individuals within months, far outstripping the infection rate of HIV or tuberculosis. The aim of this study is to identify the challenges in malaria diagnosis and elimination among in-and-out patients of Kaltungo General Hospital, located in a local government area of Gombe state, Nigeria. It is a semi-urban community hospital which covers over $\mathbf{4 0}$ rural areas and serves as a secondary health facility for 15 Primary Health Care centers (PHCs) around the area. Findings show that $70 \%$ of the challenges in malaria diagnosis and elimination is due to the life-cycle of the causative agent, Plasmodium; the most common in this rural area being Plasmodium falciparum, $20 \%$ was due to the failure of early diagnosis as a result of the attitude of the community who do not come to the hospital until the case is near death, while $10 \%$ was also found to be due to the cost of treatment. Despite efforts by successive governments to provide malaria drugs and treated nets, sharp practices among health workers and non-adherence to drug usage has made the diagnosis and elimination of malaria a herculean challenge. Four-hundred and forty-five (445) patients were diagnosed during the period of this study representing $60 \%$ of both in-and-out patients in the hospital. 345 representing $\mathbf{7 7 . 5} \%$ were diagnosed as positive for $P$. falciparum (Positive $=345 ;+100,++245$ ) while 100 representing $22.5 \%$ turned out as Not Seen (NS). 


\section{INTRODUCTION}

Recent reports have indicated improved access to malaria interventions especially in sub-Saharan Africa. Diagnostic testing for children as well as prevention treatment for pregnant women has significantly increased. According to the 2016 World Malaria report released by the World Health Organization (WHO, 2016), the estimated number of malaria cases declined by $88 \%$ while death rates declined by $90 \%$ in Africa between the year 2000 - 2015 (WHO, 2016). However, despite this heart-warming news, the scourge has not by any means lost its potency. Malaria still poses a potent threat to global health, threatening the achievement of the WHO Global Technical Strategy (GTS) for Malaria 2016 - 2030 that set an ambitious target of at least a $90 \%$ reduction in cases, incidents and mortality rate of malaria by 2030 (WHO, 2016).

According to $\mathrm{WHO}$, an estimated 212 million new malaria cases were recorded in 2015. In the same year, there were 490,000 reported deaths caused by malaria. Legacy challenges such as funding deficit, lack of adequate health care facilities and access to life saving interventions have over the years jeopardized the global fight against malaria. Interestingly, most malariarelated deaths in 2015 occurred in Africa representing $92 \%$ mortality rate. South-east Asia accounted for 6\% while Eastern Mediterranean accounted for an estimated $2 \%$. The WHO report further revealed that an estimated $\$ 2.9$ billion was spent on malaria control and elimination in 2015 alone, having increased by $\$ 0.06$ billion since 2010 (WHO, 2016).

To shrink the malaria map, a three-part strategy has been developed and is now widely endorsed (Feachem, et al., 2010).

1. Aggressive control in highly endemic countries to achieve low transmission and mortality in countries that have the highest burden of disease and death.

2. Progressive elimination of malaria from the endemic margins to shrink the malaria map

3. Research into vaccines and improved drugs, diagnosis, insecticides and other interventions, and delivery methods that reach all at risk populations.

In the past 150 years roughly, half of the countries in the world eliminated malaria. Nowadays there are 99 endemic countries - 67 are controlling malaria and 32 are pursuing elimination strategies. Efforts to control and eliminate malaria on a large scale dates back to the late $19^{\text {th }}$ century with the discovery of Plasmodium parasite and its transmission by anopheles mosquitoes. From 1945 to 2010, 79 countries eliminated malaria and despite exponential population growth in malaria endemic areas during the past 60 years, an estimated $50 \%$ of the world's population lives in malaria free areas compared with only $30 \%$ in 1950 .

Most of the progress was achieved in temperate regions where climate conditions are not as conducive to endemic malaria as they are in the tropics. Notable exceptions to this pattern include tropical island such as Maldives, Mauritius, Reunion, Taiwan and much of the Caribbean where malaria elimination was successful (Carton and Mendes, 2002).

The remarkable success was propelled by WHO's Global Malaria Eradication Program in 1955. The program relied on vector control, mainly indoor residual spraying and systematic detection and treatment of cases but abandoned in 1969, reasons for failure were technical issues of executing the strategy in Africa (Lopez et al., 2001). Other causes of malaria resurgence include changes in political and economic conditions. Despite the setbacks, there are reasons to be optimistic. Scale-up of malaria control has resulted in progress towards elimination in several countries since the early part of the $21^{\text {st }}$ century, driven by large increase in available finance for malaria and by widespread use of long-lasting insecticide-treated bed nets, artemisininbased combination therapy and rapid diagnostic tests.

WHO defines malaria elimination as "interrupting local mosquito borne malaria transmission in a defined geographical area (zero incidence of locally contracted cases, although imported cases will continue to occur)" (Schapira, 2013). Taken literally, this cannot be achieved anywhere as such outbreaks are often recorded. Therefore, Cohen and colleagues proposed a new definition as "a state where interventions have interrupted endemic transmission and limited onward transmission from imported infections below a threshold at which the risk of re-establishment is minimized" (Cohen et al., 2010). This new definition recognizes that maintaining, 'zero incidence of locally contracted cases', is not always an achievable target and emphasizes the maintenance of a highly functional surveillance and outbreak response system that is capable of preventing the re-establishment of local transmission. The definition of this state is important because a country that decides not to eliminate is not deciding to do nothing but is deciding to continue investments and programmatic activities to maintain a state of malaria control indefinitely (Feachem et al., 2010).

WHO categorizes countries in four programme phases by use of malaria slide positivity and incidence rates: control, pre-elimination, elimination and prevention of re-introduction (Schapira, 2013). For example, a country in the elimination phase has an annual parasite incidence of less than one case per 1000 people at risk.

Malaria eliminating countries share three important characteristics.

I. Most of them lie at the margins of malaria endemic regions e.g. Nigeria, Algeria, China

II. Most already have substantial malaria free areas

III. Transmission has typically been greatly reduced in recent years and incidence is generally low.

The fight against malaria is widely recognized as one of the best ways in global development. It is estimated that 
a $50 \%$ reduction in global malaria incidence could produce about $=\mathrm{N}=10,000.00$ economic benefits for every dollar invested. Malaria eradication could deliver more than $=\mathrm{N}=500$ trillion in economic benefits worldwide and more importantly save an estimated 11 million lives every year.

However, there are challenges such as:

1. Drug resistance

2. Treatment failure

3. Insecticide resistance

4. Climate change

5. Internal conflicts (like Boko Haram)

6. Lack of political will (inadequate budgetary provisions)

7. Inadequate local research efforts

8. Poor healthcare facilities for proper malaria diagnosis

9. Insufficient qualified and well trained malariologists

10. Activities of some trained and untrained health care providers.

Malaria can be eradicated but to make this happen, sustained action is required to help achieve the elimination goal. The GTS 2020 calls for elimination of malaria in 10 countries by 2020 (Edith $P$ et al., 2017). Globally, millions of deaths recorded are attributed to malaria, highlighting the need for intensified interventions from local and international authorities. If attained, the global vision of ending malaria for good will kick start a long-term transformation impact, saving millions of lives and generating huge sums.

Sustained efforts are critical to addressing the identified challenges. Local efforts should be refined and regularly updated to ensure that the global elimination agenda is routinely observed. Governments, the private sector, researchers, groups, individuals and indeed all stake-holders should act with a shared and focused goal which is to create a Nigeria in which malaria is no longer a threat to the lives and wellbeing of the citizens. The war to eliminate malaria is an assignment for everyone.

\section{METHODS/MATERIALS}

\section{Study Area:}

The study was carried out among in-and-out patients attending the General Hospital, Kaltungo, a semi-urban local government secondary health facility in Gombe state, which serves over 40 rural communities and 15 PHCs. It is located between latitude $6^{\circ} \mathrm{N}$ and longitude $10^{\circ} \mathrm{S}$ and bordered on the east by Billiri, west by Shongom, north by Bambam and south by Tula. The area has a population of 700,000 (NBS, 2010).

\section{Study Population:}

The study population is 445 made up of male and female and cuts across children, youths and adults within the age range of $5-65$ years, majority of which fall within the productive years.

\section{Laboratory Diagnosis}

The study was carried out during the harvest time over a period of 6 months when malaria usually strikes and infection rate tends to be highest. Thick and thin films made from venous blood, collected from participants in the study were stained by Giemsa's. The thin film was fixed with pure acetone free absolute methyl alcohol for 2 minutes and washed with neutral distilled water. $10 \mathrm{ml}$ of diluted Giemsa's stain was used according to the WHO standard and stained for 45 minutes. It was washed and differentiated in buffered water $\mathrm{PH} 7.0$ by two changes in one minute when the film had a pinkish grey tinge. The thick blood films were dehaemoglobinized for the quantification of parasites while the thin blood film was fixed and stained for detection of the various species, morphology of the parasites and number of the parasitized cells. The films were examined under the microscope using $\times 100$ oil immersion objectives (WHO, 2016).

\section{Study Design/Data Analysis:}

The study is a survey research using data obtained from records of in-and-out patients of the General Hospital, Kaltungo. The data was analyzed by simple arithmetic percentage and presented as in Tables $1-7$. 


\section{RESULTS}

Table I: Distribution According to Age

\begin{tabular}{|l|l|l|l|l|l|l|}
\hline AGE & $\begin{array}{l}\text { NO. } \\
\text { EXAMINED }\end{array}$ & $\%$ & $\begin{array}{l}\text { NO. } \\
\text { POSITIVE }\end{array}$ & $\%$ & $\begin{array}{l}\text { NO. NOT } \\
\text { SEEN }\end{array}$ & $\%$ \\
\hline $1-5$ & 69 & 15.5 & 66 & 18.8 & 4 & 4 \\
\hline $6-11$ & 85 & 19.1 & 75 & 21.7 & 10 & 10 \\
\hline $12-16$ & 60 & 13.5 & 55 & 15.9 & 5 & 5 \\
\hline $17-21$ & 80 & 18.0 & 60 & 17.4 & 20 & 20 \\
\hline $22-26$ & 45 & 10.1 & 44 & 12.8 & 1 & 1 \\
\hline $27-31$ & 20 & 4.5 & 8 & 2.3 & 12 & 12 \\
\hline $32-36$ & 15 & 3.4 & 7 & 2.0 & 8 & 8 \\
\hline $37-41$ & 10 & 2.2 & 4 & 1.2 & 6 & 6 \\
\hline $42-46$ & 5 & 1.1 & 2 & 0.6 & 3 & 3 \\
\hline $47-51$ & 10 & 2.2 & 8 & 2.3 & 2 & 2 \\
\hline $52-56$ & 18 & 4.1 & 11 & 3.2 & 7 & 7 \\
\hline $57-61$ & 15 & 3.4 & 2 & 0.6 & 13 & 13 \\
\hline $62+$ & 13 & 2.9 & 4 & 1.2 & 9 & 9 \\
\hline TOTAL & 445 & 100 & 345 & 100 & 100 & 100 \\
\hline
\end{tabular}

Table II: Distribution According to Sex

\begin{tabular}{|l|l|l|}
\hline SEX & NO. EXAMINED & $\%$ \\
\hline Male & 220 & 49.4 \\
\hline Female & 225 & 50.6 \\
\hline Total & 445 & 100 \\
\hline
\end{tabular}

Table III: Distribution According to marital status

\begin{tabular}{|l|l|l|}
\hline Marital status & No. examined & $\%$ \\
\hline Married & 78 & 17.5 \\
\hline Single & 205 & 46.1 \\
\hline Widowed & 95 & 21.3 \\
\hline Divorced & 22 & 4.9 \\
\hline Separated & 45 & 10.2 \\
\hline Total & 445 & 100 \\
\hline
\end{tabular}

Table IV: Distribution According to Occupation

\begin{tabular}{|l|l|l|}
\hline Occupation & No. examined & $\%$ \\
\hline Students & 102 & 22.9 \\
\hline Unemployed & 103 & 23.1 \\
\hline Employed & 240 & 54.0 \\
\hline Total & 445 & 100 \\
\hline
\end{tabular}

Table V: Distribution According to Area

\begin{tabular}{|l|l|l|}
\hline Area & No. examined & $\%$ \\
\hline Termana & 85 & 19.1 \\
\hline Kalorgu & 60 & 13.5 \\
\hline Kamu & 72 & 16.2 \\
\hline Nahinta & 15 & 3.4 \\
\hline Dogoruwa & 58 & 13.0 \\
\hline Dabio & 47 & 10.6 \\
\hline Gujuba & 61 & 13.7 \\
\hline Kaltin & 13 & 2.9 \\
\hline Sabon Layi Awak & 10 & 2.2 \\
\hline Poshere & 24 & 5.4 \\
\hline Total & 445 & 100 \\
\hline
\end{tabular}

Table VI: Distribution According to species of Malaria causative agents

\begin{tabular}{|l|l|l|}
\hline Species ID & No. examined & $\%$ \\
\hline $\begin{array}{l}\text { Plasmodium } \\
\text { falciparum }\end{array}$ & 434 & 97.5 \\
\hline $\begin{array}{l}\text { Plasmodium } \\
\text { malaria }\end{array}$ & 10 & 2.2 \\
\hline Plasmodium ovale & 1 & 0.3 \\
\hline Plasmodium vivax & 0 & 0.0 \\
\hline Total & 445 & 100 \\
\hline
\end{tabular}

Table VII: Distribution According to available drugs used in treatment

\begin{tabular}{|l|l|l|}
\hline Drugs & No. of usage & $\%$ \\
\hline Artesunate & 240 & 53.9 \\
\hline Chloroquine & 105 & 23.6 \\
\hline Amodiaquine & 5 & 1.1 \\
\hline ACTs & 60 & 13.5 \\
\hline $\begin{array}{l}\text { Sulphadoxine- } \\
\text { pyrimethanine }\end{array}$ & 35 & 7.9 \\
\hline Total & 445 & 100 \\
\hline
\end{tabular}

A total of 445 data was selected for this study. Out of the number, $225(50.6 \%)$ are female while $220(49.4 \%)$ are male (Table I) within the age range of 1 year and $62+$ (Table II). Patients aged $6-11$ accounted for significantly highest percentage positive for malaria parasites while aged $57-61$ accounted for the least percentage of positive cases (Table I). The combined active ages of $6-46$ accounted for most of the positive cases of infection indicating that a lot of man hour loss, out of school absence among school children and productivity is adversely affected due to malaria 
infection. These tally with the WHO reported cases of global malaria disease 2010.

Of the total number of participants in this study, 78 $(17.5 \%)$ of the participants are married while 205 $(46.1 \%)$ are singles (Table III). If the elimination of malaria is to be achieved, a target group of singles who are active and highly mobile should be pursued using the three-part strategy of prevention, diagnosis and treatment. This is in conformity with the success story of malaria eradication witnessed in the 1950s and 1960s according to the Lancet Report (2010).

Table IV shows the distribution of malaria infection according to occupation. 240 representing $54.0 \%$ are employed while 103 (23.1\%) and 102 (22.9\%) are unemployed and students respectively. To eliminate malaria, both the employed, unemployed and students should be a target group for the use of insecticide treated long lasting nets. Effective distribution of treated nets and spraying of our institutions of learning will greatly enhance the fight against malaria spread.

The study showed that the areas that fall into the temperate zone are the areas with the highest visits to the hospital for malaria diagnosis (Table V). Termana has 85 participants representing $19.1 \%$, Kamu (72: 16.2\%), Gujuba (61: 13.7\%) and Kalorgu (60: 13.5\%) while areas close to the Tula hills where the temperature is low has least visits - Sabon Layi Awak (10:2.2\%) and Nahinta (15: 3.4\%).

Plasmodium falciparum accounted for the most common species of malaria parasite in the study (Table $\mathrm{VI})$. It accounts for $97.5 \%$ (434) cases. This supports some earlier findings by Igwe et al (1993) which has a prevalence of $P$. falciparum malaria parasite among haemoparasites causing anaemia in a rural community in Cross River state, Nigeria. Most malaria cases were treated using Artesunate, Chloroquine and ACTs in the order of $240(53.9 \%), 105(23.6 \%)$ and 60 (13.5\%) respectively. The least used chemotherapy was Amodiaquine (5: $1.1 \%)$ while Sulphadoxinepyrimethamine is $35(7.9 \%)$.

\section{REFERENCES}

Cohen Justin M. Bruno Moonen, Robert W. Snow and David T Smith. 2010. An Evaluation of Historical and Current Definitions of Malaria elimination. Malaria Journal 9:213

Carton R. and Mendes K. N. 2002. Evolutionary and Historical aspect of the burden of Malaria. Clin Microbiol Rev 2002;15:564-94

Edith Patouillard, Jamie Griffin, Samir Bhatt, Azra Ghani and Richard Cibulskis. 2017. Global Investment targets for Malaria Control and Elimination between 2016 and 2030. BM Journal Global Health, 2017

Feachem RG ${ }^{1}$, Phillips AA, Hwang J, Cotter C, Wielgosz $B$, Greenwood BM, Sabot $O$, Rodriguez $M H$, Abeyasinghe RR, Ghebreyesus TA and Snow RW. 2010. Shrinking the Malaria map: Progress and Prospects. PubMed Journal, 6;376(9752):1566-78. doi: 10.1016/S0140-6736(10)61270-6.

Lopez A. D., Mathers C. D., Ezzati M and Murray C. H, 2001. Global Regional Burden of Disease and Risk factors 2001: Systematic Analysis of Population Health Data. Lancet 2006; 367:1747-57.

National Bureau of Statistic (NBS), Federal Government of Nigeria. 2012

Schapira A. 2013. Malaria elimination- Definitions, Criteria and Possible Advisory (WHO Malaria Policy Advisory).

World Health Organisation, 2016. Gienmsa Staining of Blood Films.

World Health Organisation, 2016. World Malaria Report 